IZA DP No. 5799

The Happiness-Income Paradox Revisited

Richard A. Easterlin

Onnicha Sawangfa

Laura Angelescu McVey

Malgorzata Switek

Jacqueline Smith Zweig

June 2011

Forschungsinstitut zur Zukunft der Arbeit Institute for the Study of Labor 


\title{
The Happiness-Income Paradox Revisited
}

\author{
Richard A. Easterlin \\ University of Southern California \\ and IZA
}

Laura Angelescu McVey

University of Southern California

Malgorzata Switek

University of Southern California

Onnicha Sawangfa

University of Southern California

\section{Jacqueline Smith Zweig \\ University of Southern California}

\author{
Discussion Paper No. 5799 \\ June 2011
}

IZA
P.O. Box 7240
53072 Bonn
Germany

Phone: +49-228-3894-0

Fax: $+49-228-3894-180$

E-mail: iza@iza.org

Any opinions expressed here are those of the author(s) and not those of IZA. Research published in this series may include views on policy, but the institute itself takes no institutional policy positions.

The Institute for the Study of Labor (IZA) in Bonn is a local and virtual international research center and a place of communication between science, politics and business. IZA is an independent nonprofit organization supported by Deutsche Post Foundation. The center is associated with the University of Bonn and offers a stimulating research environment through its international network, workshops and conferences, data service, project support, research visits and doctoral program. IZA engages in (i) original and internationally competitive research in all fields of labor economics, (ii) development of policy concepts, and (iii) dissemination of research results and concepts to the interested public.

IZA Discussion Papers often represent preliminary work and are circulated to encourage discussion. Citation of such a paper should account for its provisional character. A revised version may be available directly from the author. 
IZA Discussion Paper No. 5799

June 2011

\section{ABSTRACT}

\section{The Happiness-Income Paradox Revisited}

The striking thing about the happiness-income paradox is that over the long-term - usually a period of $10 \mathrm{y}$ or more - happiness does not increase as a country's income rises. Heretofore the evidence for this was limited to developed countries. This article presents evidence that the long term nil relationship between happiness and income holds also for a number of developing countries, the eastern European countries transitioning from socialism to capitalism, and an even wider sample of developed countries than previously studied. It also finds that in the short-term in all three groups of countries, happiness and income go together, i.e., happiness tends to fall in economic contractions and rise in expansions. Recent critiques of the paradox, claiming the time series relationship between happiness and income is positive, are the result either of a statistical artifact or a confusion of the short-term relationship with the long-term one.

JEL Classification: $\quad$ 131, O10, O5, D60

Keywords: Easterlin Paradox, life satisfaction, subjective well-being

Corresponding author:

Richard A. Easterlin

Department of Economics

KAP 300

University of Southern California

Los Angeles, CA 90089-0253

USA

E-mail: easterl@usc.edu 


\section{Introduction}

Simply stated, the happiness-income paradox is this: at a point in time both among and within nations happiness varies directly with income, but over time happiness does not increase when a country's income increases. We are talking here about the time series relationship of happiness and income in the long-term, usually at least ten years, sometimes more. As we shall see, the short-term relationship is a different story.

First reported for the United States almost four decades ago $(1,2)$ the empirical scope of the paradox has been gradually broadening to include Japan and nine developed countries of Europe in 1995 (3), and now, in this article to 17 Latin American countries, 17 developed countries, 11 eastern European countries transitioning from socialism to capitalism, and 9 less developed countries scattered across Asia, Latin America, and Africa, including some with quite low growth rates and some with the highest rates of economic growth ever observed. In addition to providing this broader range of time series evidence on the happiness-income paradox, the results of research carried on at the University of Southern California over the past five years, this article rebuts recent claims that the relationship is, in fact, positive, not nil, and contributes new evidence of the short- as well as long-term happiness-income relationship.

Our measures of happiness are life satisfaction (LS) and for the 17 Latin American countries, financial satisfaction (FS). Although questions on life satisfaction were asked in the Latin American countries, the question or response categories changed several times, making the life satisfaction data unusable for time series analysis. Although FS is a less comprehensive measure of well-being than LS, it relates directly to economic well-being; hence one would expect it to be more closely related to income change, the annual rate of change in real GDP per capita (hereafter, simply designated GDP). We use the term subjective well-being (SWB) to encompass both LS and FS. Our principal 
data sources are the Latinobarometer (LB) from Corporacion Latinobarometro (www.latinobarometro.org) and the World Values Survey (WVS) from the World Values Survey Association and the European Values Study Foundation (www.worldvaluessurvey.org and www.europeanvalues.nl) though we did use other sources as well, most notably the Eurobarometer from GESIS (www.zacat.gesis.org) for many of the developed nations.

\section{Results}

Though the product of a number of woman-and-man-years of work, the results turn out to be highly consistent and are quite concisely summarized.

1. For 17 Latin American countries, with annual time series for 1994-2006 of 10-12 years in length, the relationship between the annual growth rate of GDP and the average annual change in financial satisfaction (in absolute terms on a scale of 1-5) is nil. [Figure 1] The economic growth rates of these countries range from about -1 to 3 percent per year. Today's developed countries, at a comparable stage of development in the nineteenth century, typically averaged around 1 to 1.5 percent. In the recent experience of Latin America, it makes no difference whether a country's economic growth rate is high or low, one cannot predict the long-term change in financial satisfaction from an OLS regression analysis on the GDP data for these countries in this period. The slope coefficient of the regression does not differ in statistical significance from zero. This finding of a nil relationship is contrary to economists' usual expectation that growth and well-being would be positively related, and also to what one would expect from point-of-time cross section studies (1-8). It is consistent, however with the findings of the previous time series studies of the happiness-income relationship cited above. 
2. For a worldwide sample of 37 countries with intermittent life satisfaction data (1-10 scale) for periods ranging from 12 to 34 years (mean=22) up to 2005, there is no significant relation between the improvement in life satisfaction and the rate of economic growth. [Figure 2] The growth rates of GDP per capita here are representative of developing countries generally, typically ranging from slightly negative to almost 6 per cent. If the one outlier, China, at almost 10 percent is omitted, the regression coefficient is still not significant.

Figure 2 is for the composite of three groups of countries - developed, transition, and developing. Regressions for each of the groups separately yield results quite similar to those in Figure 2, with slope coefficients that do not differ significantly from zero, and for two of the three country groups, they are negatively signed, as in Figure 2. If a higher rate of economic growth raises financial and life satisfaction more rapidly, it is hard to find evidence of it among 17 Latin American countries, or in the richer, poorer, and transition countries studied here.

\section{Recent critiques of the Paradox}

Two types of evidence are claimed to contradict the time series findings of no relation between economic growth and happiness. The first, which is puzzling, to say the least, is cross section (point-of-time) evidence of a positive happiness-income relationship. In the economics of happiness literature this positive relationship has been well-accepted for several decades (1-10), but it is a graph based on country data from the 2006 Gallup World Poll in a 2008 article by Angus Deaton, that seems to have registered with the economics profession in general (11). This graph, which is headed "Each Doubling of GDP Is Associated with a Constant Increase in Life Satisfaction” has been cited by both economists and non-economists as disproof of the happiness-income paradox (12, 13, 
14). It is even cited in this vein in the recent Sarkozy Report (15), a landmark study, most notably in the advocacy by a group of renowned economists of the use of subjective measures of well-being such as life satisfaction for designing public policies and assessing social progress.

The essential meaning of "paradox", however, is the seeming contradiction between the first clause and the second - in this case, between the cross section and time series results. That scholars would cite Deaton's cross section results as disproving the time series finding is to ignore the very meaning of paradox. If there were no positive relation in the cross section, there would be no paradox!

In contrast, critiques based on time series findings claiming that the relationship between happiness and income is, in fact, positive must be taken seriously. The first, a 2003 study by Hagerty and Veenhoven (16) has been previously critiqued by Easterlin (17), and these criticisms, which reject the claim of a positive relationship, have been acknowledged by Hagerty and Veenhoven to be correct (18).

The second is an article by Ronald Inglehart and his collaborators (19) who suggest that the life satisfaction and happiness measures in the WVS reflect different determinants, the former, economic conditions, and the latter, political circumstances. They argue that "many ex-communist countries experienced democratization accompanied by economic collapse, resulting in rising happiness and falling life satisfaction” (p.277). The upward trend in happiness that they report, however, appears to result from a "primacy bias" in the happiness data due to a change in instructions to the interviewers between adjacent waves of the survey data they use. In one wave, interviewers were instructed to alternate the order of response choices from one respondent to the next. Thus respondent 1 would be presented with choices ranging from “very happy” down to "not at all happy,” while respondent 2 would be presented 
with "not at all happy" first. There are a number of survey studies demonstrating a tendency for respondents to favor earlier over later choices $(20,21,22)$. In this wave, therefore, half the respondents would have been more inclined toward less happy choices by virtue of being presented with the more negative options first. In the next wave, however, the "very happy" option appears first, and the instruction to alternate response options no longer appears. Hence happiness responses in this wave would tend to be biased upward relative to the preceding wave. No such change in instructions occurs in regard to the life satisfaction data, and this is why, in using the same data set here in Figure 2 as Inglehart and his collaborators, we rely on the life satisfaction measure and disregard happiness.

In fact, life satisfaction and happiness typically move together over time not in different directions and they do so in conjunction with democratization. As a striking example, consider the experience of South Africa when democracy was established there. In May 1994, one month after the country’s first democratic election, a survey was conducted that included questions about both happiness and life satisfaction. Table 1 presents for both measures the percentage of the black population in the top two (out of five) categories at that time and the corresponding percentage at the two adjacent dates when similar surveys were conducted. Note how by both measures the well-being of blacks soared at the time of the election. But as noted sociologist Valerie Møller, who kindly provided these data, observes: “[P]ost-election euphoria was short lived. Satisfaction levels have since returned to ones reminiscent of those under the former regime.”(23) This return is registered by both SWB measures. Moreover, the magnitude of rise and fall is virtually identical for the two measures. This is striking evidence, indeed, of the tendency for happiness and life satisfaction to move together, not differently. 
The third and most serious critique based on time series data is in a 2008 article by Stevenson and Wolfers (24). The main problem with the Stevenson and Wolfers (S-W) analysis is that they, in fact, estimate a positive short-term relationship between life satisfaction and GDP, rather than the long-term relationship, which is nil. That life satisfaction and GDP tend to vary together in contractions and expansions has already been demonstrated for a group of developed countries (25), and micro-level evidence consistently shows that unemployment has one of the most negative impacts on happiness $(4,8,10)$. Before proceeding to further discussion of S-W, we expand here this finding of the short-term relationship to the developing and transition countries.

We return to the Latin American data of Figure 1, the best for the short term analysis of developing countries because it is yearly (26). For both financial satisfaction and GDP we fit OLS trend lines over the full time span available for each country, and then compute the deviation at each date of the actual value from the trend value. Pooling the deviations for all 17 countries, we find that when GDP is above trend, financial satisfaction tends to be above trend; when GDP is below trend, financial satisfaction tends to be below - in short that the deviations for FS and GDP are significantly positively related. [Figure 3]

Moreover, the deviations exhibit a synchronous movement in the 17 countries; in a year when one country is below trend, almost all the others are. We therefore compute for both financial satisfaction and GDP the mean of the deviations for the 17 countries in each year. The GDP time series of mean deviations exhibits a clear pattern of collapse and recovery over the period, reflecting, in fact, the world crisis precipitated by the Asian financial crisis of 1997 which was followed by a 1998 Russian crisis. [Figure 4]. The latter especially affected commodity prices and had a great impact throughout Latin America. What is noteworthy is that the financial satisfaction time series of mean 
deviations exhibits a similar movement to GDP of collapse and recovery. Note that if one analyzes only the period 1998-2003 or 2003-2006, one concludes that happiness and income move together. But if one considers the entire period of contraction and expansion, as we do above in Figure 1, the happiness-income relation is nil. Clearly in this group of developing countries financial satisfaction and GDP are positively related in the short-term, but, as seen in the analysis in Figure 1, not in the long-term.

For the transition countries we present time series of life satisfaction and GDP for three of the countries for which the data encompass the onset of the transition [Figure 5]. The pattern is clearly like that in Figure 4, a positive relationship in the short-term. The timing of the two series is closest for the GDR, where we have annual data for both series. For Estonia and the Russian Federation, for which only intermittent life satisfaction data are available, one finds both life satisfaction and GDP with a similar Vshaped pattern. If the GDP observations are confined to those for which life satisfaction is also available, the timing pattern becomes even more similar. This synchronous Vshaped movement of both life satisfaction and GDP is typical of the transition countries for which data encompassing the onset of transition are available, but if trend lines are fitted that span both the contraction and expansion periods, we find that the long-term relationship is nil (as discussed in connection with Figure 2), in contrast to the shortterm positive relationship (27). Some analysts, who use data that do not include the contraction phase, mistakenly take the positive happiness-income relation during the expansion as indicative of the long-term trend.

To return to the Stevenson and Wolfers analysis, based on a regression analysis of data from the WVS source we use here in Figure 2, S-W report a positive relation between the change in life satisfaction and the growth rate of GDP. (We focus on their life satisfaction analysis, not happiness. As explained above there is reason to believe 
the WVS happiness data are biased upward due to a statistical artifact). Specifically, Stevenson and Wolfers report the results of three "short first differences" and three “long first differences” regressions (pp. 39-41). The 5-6 year time spans of the former are too brief to identify the long-term relation between life satisfaction and GDP. (This is much like taking for analysis either the contraction or expansion periods of Figure 4). Of the remaining three, only two have a statistically significant positive coefficient. The first (based on observations for 32 countries) is due to the inclusion chiefly of the recovery phase in 11 transition countries, rather than the complete collapse and recovery of life satisfaction and GDP in these countries (illustrated for three of them in Figure 5). If the transition countries are omitted from the regression, the coefficient is no longer significant. The other significantly positive regression coefficient, based on an analysis of 17 countries, is due entirely to two observations. The first is that for Hungary, with low growth in GDP and a negative change in life satisfaction. (Hungary is the one transition country with a data point as early as 1981; the observation for Hungary in this S-W regression analysis is based on the contraction phase of life satisfaction and GDP). The other observation is for a developing country, South Korea, with very high growth in GDP (it is off-scale in the S-W diagram), and high growth in life satisfaction. (More later on South Korea's trend in life satisfaction). If these two countries are excluded from the regression analysis, there is no significant relation in the remaining countries (all of which are developed) between the change in life satisfaction and that in GDP. Thus, the findings of a positive relationship by Stevenson and Wolfers rest almost entirely on the short-term positive association between life satisfaction and GDP in the transition countries, seen above in Figure 5. Regression lines encompassing both the contraction and expansion periods in these countries reveal a nil relation between life satisfaction and GDP (27). 
Stevenson and Wolfers also report that their typical cross section slope coefficient of 0.3 to 0.4 from regression analysis does not differ in statistical significance from their typical time series coefficient. This result is almost certainly due to the fact that their time series coefficient is much too high, because it reflects the positive short-term association between life satisfaction and GDP. Using the long-term coefficients estimated here in Figures 1 and 2, we find a statistically significant difference between these coefficients and Stevenson and Wolfer's typical cross section coefficient. Moreover, as shown in Figures 1 and 2, our regression coefficients do not differ significantly from zero.

\section{Discussion}

This article contributes the broadest range of evidence yet assembled demonstrating that over time a higher rate of economic growth does not result in a greater increase of happiness. The evidence encompasses 17 Latin American countries and, from a different data set, 17 developed countries, 11 countries transitioning from socialism to capitalism, and 9 developing countries, four of which are also in the Latin American data set.

Given the wide range of countries we were studying - rich and poor, ex-communist and capitalist, spread across five continents - we started with no preconceptions as to the likely outcome. In the end the results, from two quite different data sources, were strikingly consistent.

This article also contributes the first systematic evidence for developing and transition countries that short-term contractions and expansions are accompanied by corresponding movements in subjective well-being. Thus, in the short-term, happiness and SWB are positively related, but over the long-term - here, usually a minimum 
period of ten years - the relationship is nil. The happiness-income paradox now holds for countries ranging from poor to rich: among countries at a point in time happiness and income are positively related, but over time within a country happiness does not increase as income goes up.

The reasons for the paradoxical happiness-income relation in the long run, and why the short-term relationship is positive are beyond the scope of this article. But clearly, the escalation of material aspirations with economic growth, reflecting the impact of social comparison and hedonic adaptation, are of central importance $(26,27,28,29)$. No evidence has been forthcoming to suggest that poorer countries are somehow exempt from escalating material aspirations as income rises.

We have also considered here recent studies claiming to rebut the happiness-income paradox. One such case is where the first part of the paradox, the positive cross section relationship, is said to disprove the second, the nil time series relationship. This is, to say the least, a puzzling bit of logic, flying in the face of the very meaning of paradox. If there were no positive cross section relationship, there would be no paradox.

More pertinent are two recent time series findings purporting to show a positive happiness-income relationship. The result of the first study (19), however, is due to a statistical artifact. That of the second (24) arises from confusing the positive short-term association between happiness and income, which is what is estimated in the article, with the long-term relation, which the article does not estimate.

Although we have worked over the data used here to try to produce the most comparable time series possible (30), we make no claim to infallibility. But the fact that the surveys now available fail to pick up a positive long-term happiness-income relationship in countries exhibiting a wide disparity in economic growth rates is, to say the least, remarkable. Consider, for example, three countries included here with very 
high recent growth rates of GDP - China, South Korea, and Chile. China's growth rate implies a doubling of real per capita income in less than 10 years; South Korea's, in 13 years; and Chile's, in 18 years. With the real per capita amount of goods multiplying so rapidly in a fraction of a lifetime, one might think many of the people in these countries would be so happy, they'd be dancing in the streets. Yet both China and Chile show mild (not statistically significant) declines in life satisfaction - China in surveys conducted by three different statistical organizations. South Korea, none of whose surveys have been faulted, shows a (not statistically significant) increase. All of the increase, however, results from a low life satisfaction value reported in the initial survey, one that was conducted a few months after the assassination of the country's president in 1980. Thereafter, in four surveys from 1990 to 2005, a period when per capita GDP continued to grow rapidly, averaging 5 percent per year, life satisfaction declines slightly (though the decline is not statistically significant). With incomes rising so rapidly in these three different countries, it seems extraordinary that there are no surveys that register the marked improvement in subjective well-being that mainstream economists and policy makers worldwide would expect to find.

Where does this leave us? If economic growth is not the main route to greater happiness, what is? A simple, but unhelpful answer, is that more research is needed. Possibly more useful are studies that point to the need to focus policy more directly on urgent personal concerns relating to such things as health and family life and to the formation of material preferences (28), rather than on the mere escalation of material goods.

\section{Materials and Methods}


The data underlying Figures 1, 3 and 4 are from the Latinobarometer (LB) conducted almost annually since 1995 in 17 countries throughout Latin America. Prior to 2003, the LB survey coverage of smaller places in some countries was very uneven. For this reason, we confined our time series analysis to places of 100,000 population or more in the following countries: Ecuador, El Salvador, Guatemala, Honduras, Nicaragua, Panama, Uruguay. The remaining countries, for which the data for places of 100,000 population were used in the early survey years for which the coverage of small places was particularly poor, and the national values were employed thereafter, are: Argentina, Bolivia, Brazil, Costa Rica, Colombia, Chile, Mexico, Paraguay, Peru and Venezuela. (In point of fact, the reported national values for FS in these countries do not differ much from those for places of 100,000 population or more).

The data principally underlying Figures 2 and 5 are from the World Values Survey, conducted in an increasing number of countries throughout the world in five waves: 1981-84, 1989-93, 1994-99, 1999-2004 and 2005-2007, and the Eurobarometer surveys conducted between 1973 and 2006. Of the developing countries included here, the following were first surveyed in wave 2, and thus have 4 time series observations: Brazil, Chile, China, South Africa, and Turkey. Four developing countries were first surveyed in wave 1 and have 5 time series observations: Argentina, Japan (whose initial time series observation puts it well within the developing bloc), Mexico and South Korea. When possible we check our data against other surveys (China, Japan and South Africa). The eleven transition countries comprise Bulgaria, Czech Republic, Estonia, German Democratic Republic, Hungary, Latvia, Lithuania, Poland, Romania, Russian Federation, and Slovakia. The 17 developed countries are Australia, Belgium, Canada, Denmark, France, Germany, Great Britain, Greece, Italy, Ireland, Luxembourg, Netherlands, Northern Ireland, Norway, Portugal, Spain, and the United States. For the 
United States, the data are from the General Social Survey from the National Opinion Research Center ${ }^{1}$. For Australia and Canada they are from the World Values Survey. Times series happiness data for Norway were kindly provided by Professor Ottar Hellevik. The rest of the developed countries were surveyed as part of the Eurobarometer. The GDP data are those of the World Bank's World Development Indicators (http://go.worldbank.org/IW6ZUUHUZ0), from 1975 onwards.

We date the observations on subjective well-being (SWB) here, not at the actual survey dates, but to match the annual GDP observations that they most likely represent. The GDP dates are for calendar years while the SWB surveys typically relate to only one or a few months at various points in a year; hence an SWB survey in the first part of the year is likely to reflect economic conditions in the previous year.

The LB question on financial satisfaction is: How would you define, in general, the current economic situation of your family? Would you say it is 1=very good, 2=good, $3=$ regular, 4=bad, 5=very bad. We recoded the responses to go from 5=very good on down. The WVS question on life satisfaction is: All things considered, how satisfied are you with your life as a whole these days? Please use this order to help your answer:

$\begin{array}{llllllllll}1 \text { Dissatisfied } & 2 & 3 & 4 & 5 & 6 & 7 & 8 & 9 & 10 \text { Satisfied }\end{array}$ We compute the long term growth rate of SWB by regressing it on time, taking as our period of analysis for each country the largest time span available (minimum, 10 years for LB, 12 years for WVS). The long term growth rate of GDP is computed from the GDP per capita values at the start and end of the period covered by the SWB observations. Growth rates for both SWB and GDP are per year; the change in SWB is

\footnotetext{
${ }^{1}$ Davis JA, Smith TW. General Social Surveys 1972-2008. Principal Investigator Davis JA, Director and Co-Principal Investigator Smith TW, Co-Principal Investigator Marsden PV. NORC ed. Chicago: National Opinion Research Center, producer, 2005; Storrs, CT: The Roper Center for Public Opinion Research, University of Connecticut, distributor.
} 
measured in absolute terms, that in GDP in percentage terms (hence the use of log GDP).

In taking long periods for analysis the purpose is specifically to distinguish the longer from the shorter term relationship. The ordinary least squares regressions in Figures 1 and 2 are for the rate of change in SWB (absolute amount) regressed on the log GDP per capita. The methods underlying Figures 3 and 4 are detailed in the text. Figure 5 is

a plot of the absolute value of life satisfaction and an index of real GDP per capita $(1989=100)$.

ACKNOWLEDGMENTS. For helpful comments we are grateful to Andrew E. Clark, Carol Graham, and Andrew J. Oswald. We thank Emily Page for helpful assistance.

\section{References}

1. Easterlin RA (1973) Does Money Buy Happiness? Publ Interest 30: 3-10.

2. Easterlin RA (1974) in Essays in Honour of Moses Abramovitz, eds David PA, Reder MS (Academic Press), pp 89-125.

3. Easterlin RA (1995) Will Raising the Incomes of all Increase the Happiness of All? J Econ Behav Organ 27(1): 35-47.

4. Frey BS, Stutzer A (2002) Happiness and Economics: How The Economy and Institutions Affect Well-Being (Princeton University Press).

5. Frey BS, Stutzer A, (2002) What Can Economists Learn From Happiness Research? J Econ Lit 40(2): 402-435.

6. Graham C, Pettinato S (2002) Happiness and Hardship: Opportunity and Insecurity in New Market Economies (The Brookings Institution). 
7. Inglehart R (1988) The Renaissance of Political Culture. Am Polit Sci Rev 82(4): 1203-30.

8. Layard R (2005) Happiness: Lessons from a New Science (Penguin Press).

9. See Easterlin RA (2005) Diminishing Marginal Utility of Income? Caveat Emptor. Soc Indic Res 70(3):243-55 and the citations therein.

10. Oswald AJ (1997) Happiness and Economic Performance. Econ J 107(445):18151831.

11. Deaton A (2008) Income, Health, and Well-Being around the World: Evidence from the Gallup World Poll. J Econ Perspect 22(2):53-72.

12. Arrow KJ, Dasgupta PS (2009) Conspicuous Consumption, Inconspicuous Leisure. Econ J 119(541):F500,F513.

13. Guriev S, Zhuravskaya E (2009) (Un)happiness in Transition. J Econ Perspect 22(2):152.

14. Bok D (2010) The Politics of Happiness: What Government Can Learn from the New Research on Well-Being (Princeton University Press) p 67.

15. Stiglitz JE, Sen A, Fitoussi JP (2009) Report of the commission on the measurement of economic performance and social progress. CMEPSP p 149.

16. Hagerty MR, Veenhoven R (2003) Wealth and Happiness Revisited - Growing National Income Does Go with Greater Happiness. Soc Indic Res 64(1): 1-27.

17. Easterlin RA (2005) Feeding the Illusion of Growth and Happiness: A Reply to Hagerty and Veenhonven Soc Indic Res 74(3): 429-43.

18. Hagerty MR, Veenhoven R (2006) Rising Happiness in Nations 1946-2004: A Reply to Easterlin. Soc Indic Res 79(3): 421-436. 
19. Inglehart R, Foa R, Peterson C, Wetzel C (2008) Development, Freedom, and Rising Happiness: A Global Perspective (1981-2007). Perspect Psychol Sci 3(4): 26485.

20. Belson WA (1966) The Effects of Reversing the Presentation Order of Verbal Rating Scales. J Advert Res 6(4): 30-37.

21. Chan JC (1991) Response-Order Effects in Likert-type Scales. Educ Psychol Meas 51(3):531-40.

22. Schuman H, Presser S (1981) Questions and Answers in Attitude Surveys: Experiments on Question Form, Wording and Context (Academic Press), pp 56-77. We tried to test for a primacy bias, but were unable to identify which respondents received the positive option first, and which the negative option.

23. Møller V (2007) in Wellbeing in Developing Countries: From Theory to Research, eds Gough I, McGregor JA (Cambridge University Press), pp 242-258.

24. Stevenson B, Wolfers J (2008) Economic Growth and Subjective Well-Being: Reassessing the Easterlin Paradox. Brookings Paper Econ Activ 2008(Spring):1-87.

25. DiTella R, MacCulloch RJ, Oswald AJ (2001) Preferences over Inflation and Unemployment: Evidence from Surveys of Happiness. Am Econ Rev 91(1):335-341.

26. Graham C (2009) Happiness Around the World: The paradox of happy peasants and miserable millionaires (Oxford University Press).

27. Easterlin RA (2009) Lost in Transition: Life Satisfaction on the Road to Capitalism. J Econ Behav Organ 71(2):130-145.

28. Easterlin RA (2003) Explaining Happiness. Prod Natl Acad Sci 100(19):1117611183.

29. Clark AE, Frijters P, Shields MA (2008) Relative Income, Happiness, and Utility: An Explanation for the Easterlin Paradox and Other Puzzles. J Econ Lit 46(1):95-144. 
30. Easterlin RA, Sawangfa O (2010) in International Differences in Well-Being, eds Diener E, Helliwell JF, Kahneman D (Oxford University Press), Appendixes B and C. 


\section{Tables and Figures}

Table 1. Percentage of black population in top two response categories of happiness and of life satisfaction: South Africa 1988, 1994, 1995

\begin{tabular}{lccc} 
& 1988 & 1994 & 1995 \\
\hline Happiness & 32 & 80 & 39 \\
Life & 37 & 86 & 45 \\
Satisfaction & & &
\end{tabular}

Source: South Africa Quality of Life trends Study commissioned to Mark Data. We are grateful to Prof. Valerie Møller for providing these data to us. The survey samples are weighted to be representative of the actual black population.

Figure 1. Average annual rate of change in Financial Satisfaction and in GDP per capita, 17 Latin American countries, 1994-2006

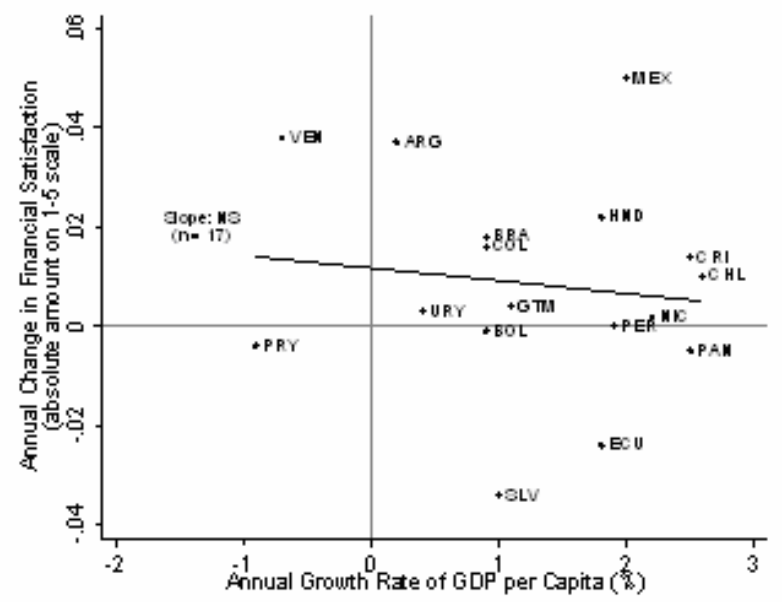

The fitted OLS regression is: $\mathrm{y}=-.255 \mathrm{x}+0.12$ (adj $\mathrm{R}^{2}=-0.05$ ); $\mathrm{t}$-stats in parentheses.

(0.5) (1.42) 
Figure 2. Average annual rate of change in Life Satisfaction and in GDP per capita, 17 developed, 11 transition, and 9 developing countries

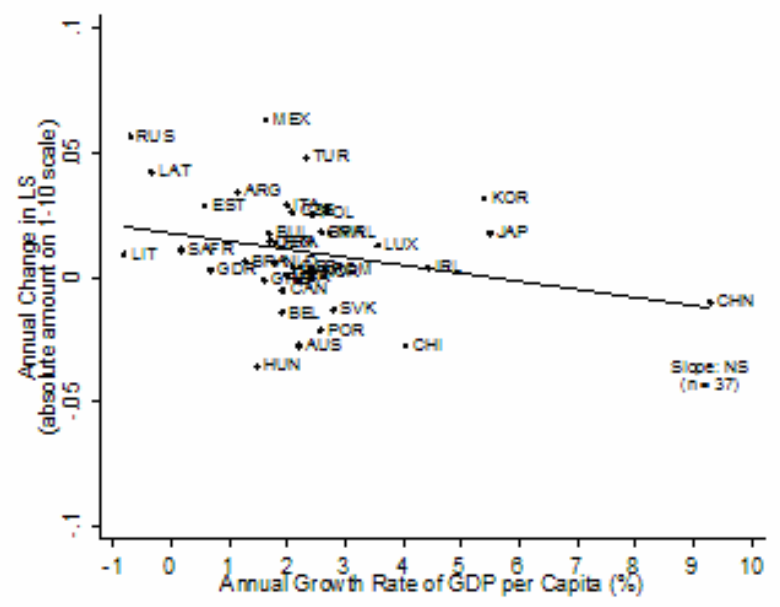

The fitted OLS regression is: $y=-0.003 x+0.018\left(\operatorname{adj~} R^{2}=0.069\right)$; t-stats in parentheses.

$(-1.61) \quad(3.07)$

Figure3. Deviations from trend in Financial Satisfaction and in log GDP per capita, 17 Latin American countries (n=175), 1994-2006

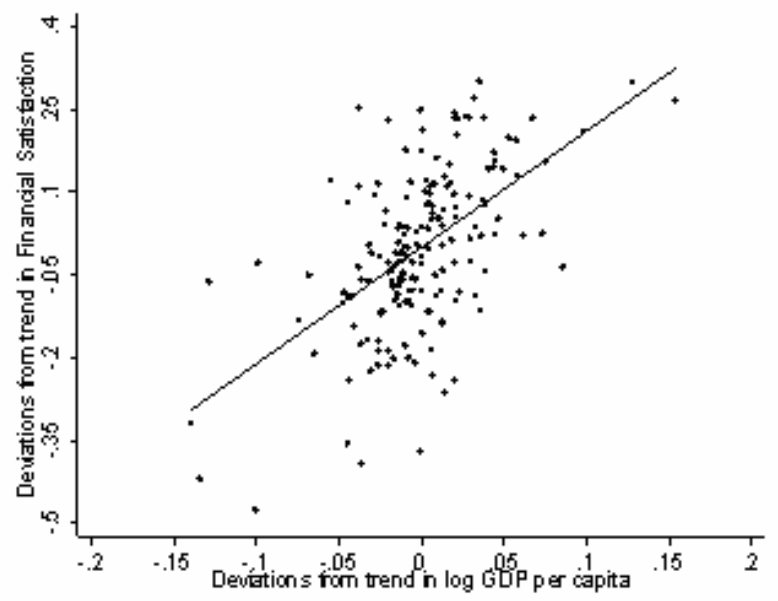

For each country the plotted values are the deviations of the actual magnitude in a given year (Table A-1) from the trend value for that year as given by the regression equations in Tables 1 and 2. The fitted OLS regression is $y=2.11 \mathrm{x}$ (adj $\mathrm{R}^{2}=0.31$ ); t-stats in parentheses. 
Figure4. Mean deviation in Financial Satisfaction and in log GDP per capita, 17 Latin American countries, annually 1994-2006

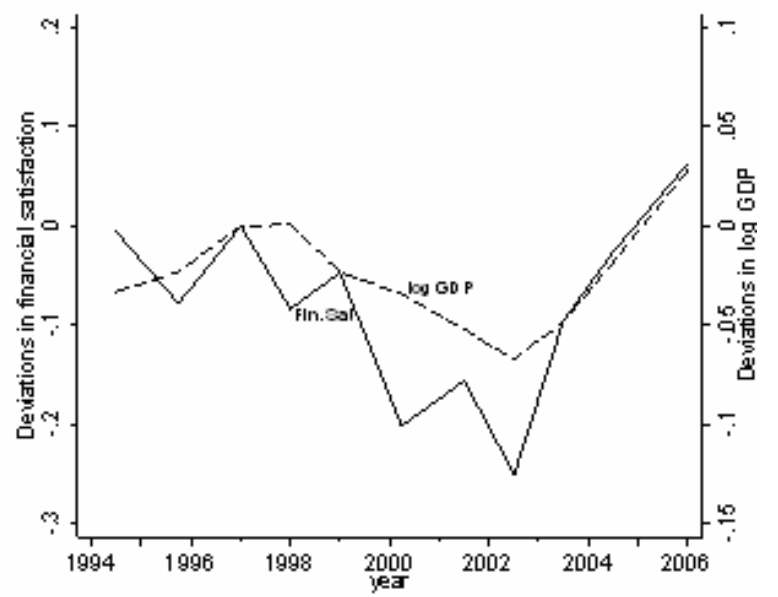

See text for methods. 
Figure5. Life Satisfaction and Annual Index of Real GDP, 3 transition countries, 1989-2005

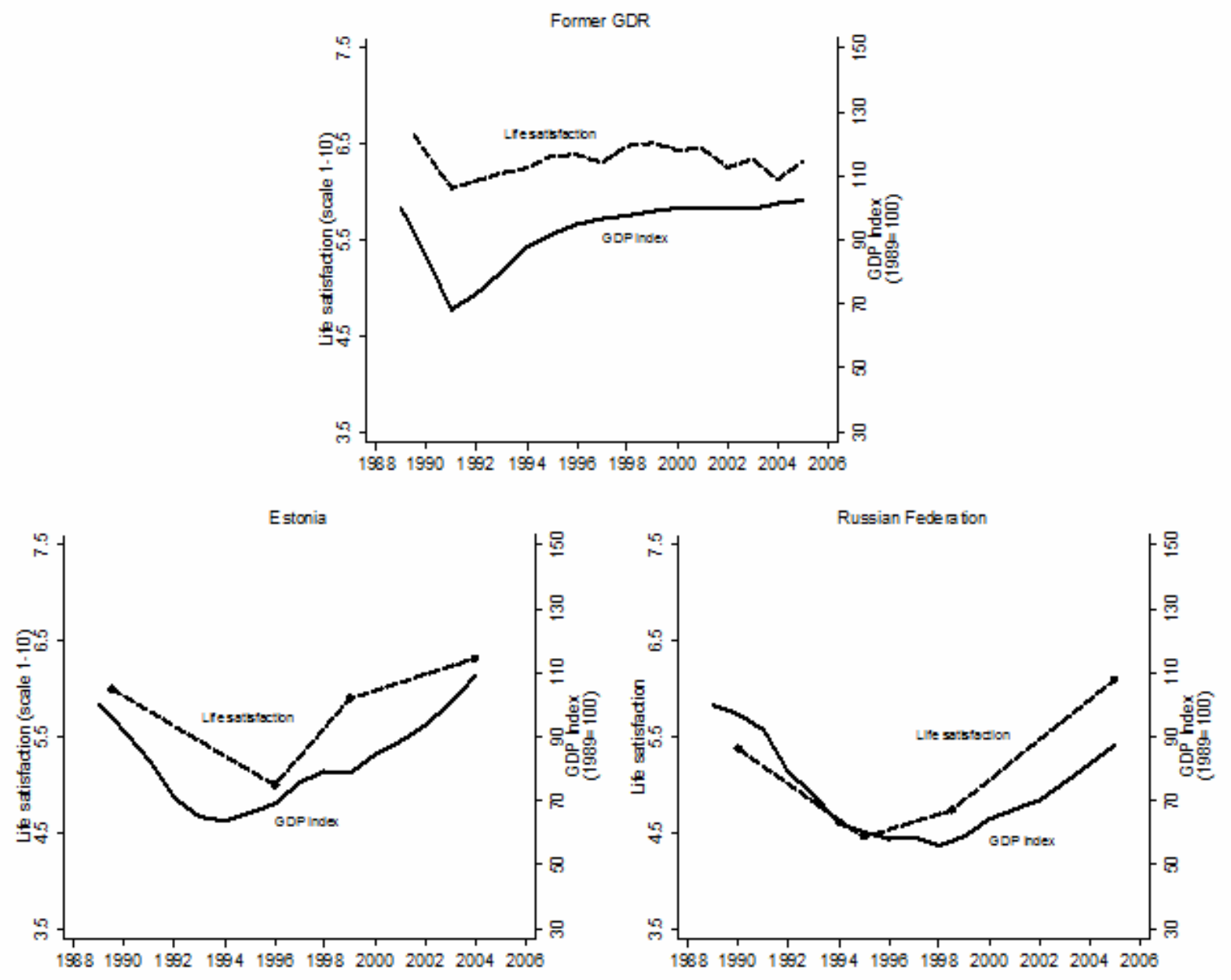

Source: 30. 